\title{
Long-term performance and microbial community characterization of an osmotic anammox system for removing reverse-fluxed ammonium
}

\author{
Xiaojin $\mathrm{Li}^{\mathrm{a}}$, Shan Sun ${ }^{\mathrm{b}}$, Brian D. Badgley ${ }^{\mathrm{b}}$, Zhen $\mathrm{He}^{\mathrm{a}, *}$ \\ ${ }^{a}$ Department of Civil and Environmental Engineering, Virginia Polytechnic Institute and State \\ University, Blacksburg, VA 24061, USA \\ ${ }^{\mathrm{b}}$ Department of Crop and Soil Environmental Sciences, Virginia Polytechnic Institute and State \\ University, Blacksburg, VA 24061, USA
}

Intended for Bioresource Technology

Type of Contribution: Research Article

*Corresponding author. E-mail: zhenhe@vt.edu; Tel.: +1 (540) 231 1346; fax: +1 (540) 231 7916. 


\begin{abstract}
A novel osmotic anammox (OsAMX) system coupling nitritation-anammox with forward osmosis (FO) has been developed for removal of reverse-fluxed ammonium when using $\mathrm{NH}_{4} \mathrm{HCO}_{3}$ as a draw solute. In this study, long-term performance and microbial community structure were investigated. The nitritation-anammox reactor maintained an ammonium concentration of $7.0 \pm 5.0 \mathrm{mg} \mathrm{N} \mathrm{L}^{-1}\left(\mathrm{DO}=0.9 \pm 0.2 \mathrm{mg} \mathrm{O}_{2} \mathrm{~L}^{-1}\right.$ ), while the FO achieved a water flux of $2.3 \pm 0.4 \mathrm{LMH}\left(0.5 \mathrm{M} \mathrm{NH}_{4} \mathrm{HCO}_{3}\right.$ draw $)$. The low water flux was obtained likely due to concentration polarization, reverse salt flux (RSF) and membrane fouling. Sequencing analyses reveled that Candidatus Jettenia was the dominant anammox genus, while Ca. Brocadia was most abundant in biofilm. The shift of anammox bacterial population indicated possible higher tolerance for DO or elevated RSF of $\mathrm{Ca}$. Brocadia. These results encourage further investigation of OsAMX system optimization, membrane fouling migration strategies, and application with actual wastewater.
\end{abstract}

Keywords: Forward osmosis; nitritation-anammox; reverse salt flux; membrane fouling; microbial community 


\section{Introduction}

Forward osmosis (FO) is an emerging membrane technology for separation/desalination and has also been applied to biological treatment of wastewater (Lutchmiah et al., 2014). In an FO process, a semipermeable membrane is placed between a concentrated draw solution and a diluted feed solution, creating a natural osmotic pressure difference as a driving force for water transport across the membrane (Shaffer et al., 2015). FO has potential applications in sustainable water/wastewater treatment for producing high quality water. It may address several drawbacks of conventional hydraulic pressure-driven membrane processes (e.g., reverse osmosis, RO), including intensive energy consumption due to high hydraulic pressure, extensive pretreatment requirements to maintain long-term operation of membrane modules, and decreasing permeability caused by membrane fouling (Linares et al., 2014). However, despite the recent advancements in FO, its shortcomings have also been highlighted, such as relatively low water flux and high energy demand for draw solute recovery; especially, reverse solute leakage can result in increase in operational cost and decline in driving force, as well as the potential environmental issues due to release of the concentrated feed solution containing pollutants (Qin \& He, 2014). Selection of an appropriate draw solute is critically important to address some of the above challenges.

Since 2005, the application of thermolytic ammonia-carbon dioxide (ammonium bicarbonate) as a draw solute has accelerated the development of FO technology (McCutcheon et al., 2005). The vapor pressure of ammonium bicarbonate is much higher than that of water, so that it can be easily decomposed into ammonia and carbon dioxide from the draw solution at a moderate temperature (e.g., $60-80^{\circ} \mathrm{C}$ ), which can significantly reduce energy demand for fresh water 
recovery and draw solute regeneration (McCutcheon et al., 2005). Like other draw solutes, the diffusive loss of ammonium bicarbonate from draw side via reverse salt flux (RSF) is unavoidable, which could not only impede the performance of FO process (reduction of osmotic pressure) but also contaminate feed solution (increased ammonium concentration). Therefore, removal of reverse-fluxed ammonia is of great importance to maintain osmotic pressure and reduce contaminant discharge.

An osmotic anammox system (OsAMX) was successfully demonstrated by synergistically linking anaerobic ammonium oxidization (anammox) to FO for autotrophic removal of reversefluxed ammonium (Li et al., 2015). In the OSAMX system, part of the reverse-fluxed ammonium is oxidized to nitrite by ammonium oxidizing bacteria (AOB), and then the produced nitrite and the remaining ammonium is converted to nitrogen gas and nitrate by anammox bacteria. Under a continuously operating mode, the OsAMX achieved a water flux of $2.5 \pm 0.2 \mathrm{LMH}\left(\mathrm{L} \mathrm{m}^{-2} \mathrm{~h}^{-1}\right)$ when using $0.5 \mathrm{M} \mathrm{NH}_{4} \mathrm{HCO}_{3}$ as the draw solution. Meanwhile, the ammonium concentrations were maintained at $3.1 \pm 4.2 \mathrm{mg} \mathrm{N} \mathrm{L}^{-1}$ and $12.8 \pm 6.4 \mathrm{mg} \mathrm{N} \mathrm{L}^{-1}$ in the anammox effluent and the FO feed side, respectively. The proposed OsAMX system has several merits. For example, it can maintain a large osmotic pressure for achieving desired water flux by preventing the accumulation of reverse-fluxed ammonium in the feed solution. In addition, the feed solution does not require intensive post-treatment due to the in situ removal of ammonium. However, the long-term performance of the system under varied conditions is still unclear, and the composition of microbial community in such a system has not been studied. In addition, the performance of an FO process can be affected by membrane fouling (Mi \& Elimelech, 2008). The occurrence of membrane fouling is associated with several factors, including metabolic products produced by 
microorganisms, inorganic matters in feed solution and biofilm formed on membrane surface (Lee et al., 2010; Mi \& Elimelech, 2010). Understanding the fouling mechanisms is essential for the development of corresponding mitigation strategies, thereby further promoting the commercial potential of FO in various applications (Shaffer et al., 2015).

To further understand the OsAMX system and its microbial community, this study was conducted with the objectives for: (1) investigation of the effects of draw solute concentrations on both anammox and FO; (2) examination of bidirectional mass transport of solutes in the FO under varied operating conditions; and (3) analysis of microbial community structure in both granules and biofilm (formed on the FO membrane) to reveal their functions in nitrogen transformation. Initial evaluation of membrane fouling mechanisms over a long-term period was conducted as a part of the performance of the OsAMX system.

\section{Methods}

\subsection{OsAMX setup and operation}

The schematic of a lab-scale OsAMX system is shown in Fig. 1. The system connected an upflow nitritation-anammox reactor (height $0.75 \mathrm{~m}$, diameter $0.05 \mathrm{~m}$ ) with an FO unit through the recirculation of the feed solution at a rate of $34 \mathrm{~mL} \mathrm{~min}^{-1}$, resulting in an upflow velocity of $1.04 \mathrm{~m} \mathrm{~h}^{-1}$. The cellulose triacetate (CTA) membrane with a surface area of $0.01 \mathrm{~m}^{2}$ (Hydration Technologies Inc., Albany, OR, USA) was used as FO membrane. Two pieces of CTA membrane were installed with their active layer facing the feed solution, creating a volume of 75 $\mathrm{mL}$ in the draw side. The nitritation-anammox reactor and the feed side of FO unit had a working volume of $1.5 \mathrm{~L}$ and $2 \mathrm{~L}$, respectively. The $\mathrm{pH}$ inside the nitritation-anammox reactor was 
maintained between 7 and 8 by adding $0.5 \mathrm{M} \mathrm{NaOH}$ solution when necessary. A heating rod was used to maintain the temperature of $30 \pm 1^{\circ} \mathrm{C}$ in the feed side, resulting in a temperature of $24-$ $28^{\circ} \mathrm{C}$ in the nitritation-anammox reactor. Aeration in the feed side was controlled by a gas flow meter based on dissolved oxygen (DO) level and reactor performance.

The nitritation-anammox reactor was initially inoculated with a mixed biomass mainly containing anammox bacteria. The reverse-fluxed ammonium from the draw side was the sole ammonium source for microorganisms. The extracted water from the nitritation-anammox reactor was compensated by a mineral solution, which was prepared according to a previous study (Li et al., 2015): $\mathrm{NaHCO}_{3} 0.42 \mathrm{~g} \mathrm{~L}^{-1}, \mathrm{KH}_{2} \mathrm{PO}_{4} 0.0272 \mathrm{~g} \mathrm{~L}^{-1}, \mathrm{MgSO}_{4} 0.059 \mathrm{~g} \mathrm{~L}^{-1}$,

$\mathrm{CaCl}_{2} \cdot 2 \mathrm{H}_{2} \mathrm{O} 0.18 \mathrm{~g} \mathrm{~L}^{-1}, 1 \mathrm{~mL} \mathrm{~L}^{-1}$ trace elements solution I and $1 \mathrm{~mL} \mathrm{~L}^{-1}$ trace elements solution II. The draw solute with varied concentration from $0.5 \mathrm{M}$ to $2 \mathrm{M}$ was fed to the draw side continuously at a rate of $228 \mathrm{~mL} \mathrm{~d}^{-1}$ (hydraulic retention time $(\mathrm{HRT})$ of draw solution = $7.9 \mathrm{~h}$ ) and was recirculated at $100 \mathrm{~mL} \mathrm{~min}{ }^{-1}$ (flow velocity of $0.42 \mathrm{~cm} \mathrm{~s}^{-1}$ ). The HRT of the nitritationanammox reactor was varying depending on the water flux of the FO (3.1 $\pm 0.1 \mathrm{~d})$. The experiment consisted of five stages, and the draw solution characteristic, operating duration for each stage are shown in Table S1.

\subsection{Measurement and analysis}

The concentrations of ammonium $\left(\mathrm{NH}_{4}{ }^{+}-\mathrm{N}\right)$, nitrite $\left(\mathrm{NO}_{2}{ }^{-} \mathrm{N}\right)$ and nitrate $\left(\mathrm{NO}_{3}{ }^{-}-\mathrm{N}\right)$ were measured regularly by using a spectrophotometer (DR 890, Hach Company, Loveland, CO, USA). The concentrations of nitrogenous ions in the feed side were similar to those of the anammox effluent because of liquid recirculation; thus, the data measured from the anammox 
effluent were reported in this study. Ion concentrations were quantified using ion chromatography (Dionex LC20 ion chromatograph, Sunnyvale, CA, USA) equipped with an ED40 electrochemical detector. The conductivity and $\mathrm{pH}$ were measured with a benchtop conductivity meter (Mettler-Toledo, Columbus, OH, USA) and a benchtop pH meter (Oakton Instruments, Vernon Hills, IL, USA), respectively. The online pH/ORP control system (Milwaukee Instruments, Inc., Rocky Mount, NC, USA) was employed to monitor the $\mathrm{pH}$ and redox condition in the system. DO was measured regularly by a portable DO meter (Hanna Instruments Inc., Woonsocket, RI, USA). The calculation for water flux ( $\left.\mathrm{LMH}, \mathrm{L} \mathrm{m}^{-2} \mathrm{~h}^{-1}\right)$, the reverse salt flux (RSF, $\mathrm{g} \mathrm{N} \mathrm{m}^{-2} \mathrm{~h}^{-1}$ ) and salt rejection (R, \%) was according to the previous study (Li et al., 2015).

\subsection{Scanning electron microscope (SEM)}

Surface morphology and structural properties of the biomass samples were examined using a thermally assisted field emission (FESEM) (LEO 1550, Carl Zeiss, Oberkochen, Germany), which was operated at an accelerating voltage of $5 \mathrm{kV}$. Prior to observation, granule samples were pretreated following a series of steps, including fixation with 4\% paraformaldehyde and 0.1 M phosphate buffered saline (PBS) (10 min), dehydration with a graded ethanol series (30\%, 50\%, 70\%, 95\%, 5 min each), drying with a critical point drier (model 28000, LADD Research Industries, Williston, VT), and finally sputter coating with Au/Pd layer ( $\sim 10 \mathrm{~nm})$.

\subsection{Fluorescence in situ hybridization (FISH)}

FISH was employed to illustrate the spatial distribution of microorganisms in the granule and the biofilm, including ammonia-oxidizing bacteria (AOB), nitrite-oxidizing bacteria (NOB), 
anammox bacteria, etc. The granular or/and biofilm samples were harvested under various operating conditions. The 16S rRNA targeted-oligonucleotide probes (Sigma-Aldrich, St. Louis, MO, USA) used here are listed in Table S2. The preparation of sample slides was performed according to a previous study (Okabe et al., 1999). The hybridized samples were observed by confocal laser scanning microscopy (CLSM) (Zeiss LSM 880, Jena, Germany) equipped with an Ar laser (488 nm) and two He-Ne lasers (543 nm and $633 \mathrm{~nm}$ ).

\subsection{DNA extraction and Illumina sequencing}

Biomass samples for DNA sequencing analysis were harvested at different operating stages, including initial anammox granules for inoculation, granule samples taken on day 50 when using $0.5 \mathrm{M}$ draw solution, as well as granule and biofilm samples taken on day 126 when using $1.5 \mathrm{M}$ draw solution. Biomass samples were extracted with the PowerSoil DNA extraction kit (MoBio Laboratories, Carlsbad, CA, USA) following the manufacturer's instructions. Extracted DNA was quantified with spectroscopic methods (NanoDrop 2000, Thermo Fisher Scientific, Beverly, MA, USA). The V4 region of bacterial 16S rRNA gene was amplified with forward primer 515F and reverse primer 806R (Caporaso et al., 2012). The amplification was carried out in $25 \mu \mathrm{L}$ reactions containing $10 \mu \mathrm{L} 2.5 \mathrm{X} 5$ Prime HotMaster mix (5 Prime, Gaithersburg, MD), $13 \mu \mathrm{L}$ PCR water (MoBio Laboratories, Carlsbad, CA, USA), $0.5 \mu \mathrm{L}$ of each of the primers $(10 \mu \mathrm{M})$, and $1 \mu \mathrm{L}$ of isolated DNA. The thermal cycler protocol was $94{ }^{\circ} \mathrm{C}$ for $5 \mathrm{~min}, 35$ cycles of $94{ }^{\circ} \mathrm{C}$ for $45 \mathrm{~s}, 50{ }^{\circ} \mathrm{C}$ for $45 \mathrm{~s}$, and $72{ }^{\circ} \mathrm{C}$ for $90 \mathrm{~s}$ and a final extension at $72{ }^{\circ} \mathrm{C}$ for $10 \mathrm{~min}$. All PCR reactions were performed in triplicate on thermal cyclers (Bio-Rad, Hercules, CA, USA) and run in agarose gel. Amplicons were purified with UltraClean PCR cleanup kit (MoBio Laboratories, Carlsbad, CA, USA) and quantified with Qubit 2.0 fluorometer (Invotrogen, USA). 
Purified amplicons were pooled in equimolar concentrations and sequenced on the Illumina Miseq platform at Virginia Bioinformatics Institute. Raw data from sequencing were processed with USEARCH pipeline (Edgar, 2010). The forward and reverse reads were merged and filtered with minimum length and expected errors. The high quality reads were then binned into 679 operational taxonomic units (OTUs) with a 97\% identity threshold, and chimeric sequences were identified and removed with UCHIME (Edgar, 2013). Taxonomy was assigned with the RDP classifier with the SILVA databases in QIIME environment (Caporaso et al., 2010; Wang et al., 2007). Illumina sequencing data are archived in the NCBI Sequence Read Archive (SRA) under accession SRP067883.

\section{Results and discussion}

\subsection{Long-term performance of the OsAMX system}

The OsAMX system was continuously operated over 160 days with varied concentration of $\mathrm{NH}_{4} \mathrm{HCO}_{3}$. Due to the interaction between biological reactions and membrane permeability, the concentration of ammonium in the nitritation-anammox reactor (and feed side) was fluctuated during the experimental period (Fig. 2A and 2B). With $0.5 \mathrm{M} \mathrm{NH}_{4} \mathrm{HCO}_{3}$ as draw solution (days 1-53), the concentrations of ammonium and nitrate were observed as $7.0 \pm 5.0$ and $36.0 \pm 11.5$

mg N L ${ }^{-1}$, respectively. In contrast, a very low nitrite concentration was achieved in the system $\left(0.1 \pm 0.0 \mathrm{mg} \mathrm{N} \mathrm{L}^{-1}\right)$. When increasing the concentration of the draw solute, the ammonium and nitrate concentrations went up and down occasionally, and did not exhibit strong correlation with the applied draw solute (Fig. 2B). However, regardless of varied concentration of the draw solute, the average nitrite concentration was less than $0.6 \mathrm{mg} \mathrm{N} \mathrm{L}^{-1}$ 
(Fig. 2B), while the conductivity in both the nitritation-anammox reactor and the feed side was successfully maintained at a low level $\left(<2.5 \mathrm{mS} \mathrm{cm}^{-1}\right.$, Fig. 2C and S1) due to the removal of reverse-fluxed ammonium and forward solute flux (Fig. 3). In addition, the DO concentration was controlled below $2 \mathrm{mg} \mathrm{O}_{2} \mathrm{~L}^{-1}$ in the feed side (Fig. S1), resulting in a lower DO level of 0.9 $\pm 0.2 \mathrm{mg} \mathrm{O}_{2} \mathrm{~L}^{-1}$ in the nitritation-anammox reactor (Fig. 2C), suggesting that oxygen was consumed by microbial metabolism (e.g., nitrification process).

The FO performance with respect of water flux and reverse salt flux is shown in Fig. 3. Water flux did not show any obvious change in accordance with increasing concentration of the draw solute. The maximum water flux of 3.2 LMH (average $2.3 \pm 0.4 \mathrm{LMH}$ ) was achieved when using $0.5 \mathrm{M} \mathrm{NH}_{4} \mathrm{HCO}_{3}$ as draw solution. The water flux decreased to $1.8 \mathrm{LMH}$ when supplying 0.75 and $1 \mathrm{M} \mathrm{NH}_{4} \mathrm{HCO}_{3}$ as draw solution, while it slightly increased to $\sim 2 \mathrm{LMH}$ after replacing with 1.5 and $2 \mathrm{M} \mathrm{NH}_{4} \mathrm{HCO}_{3}$. The water flux was much lower than expected, likely due to concentration polarization (CP), RSF and membrane fouling. Two types of CP exist in the FO process, including external CP (ECP) and internal CP (ICP). In the present FO unit, the feed solution (anammox effluent) is channeled on the active layer of the membrane (i.e., dense rejection layer) while the draw solution (ammonia bicarbonate) is channeled on the support layer (i.e., backing layer). Such configuration is to mimic the typical FO desalination module where the feed solution is directed against the active layer (McCutcheon et al., 2006), and to reduce biofouling by avoiding the feed solution (potentially containing biomass) facing the support layer with porous substructure. As water permeates the active layer, the draw solution within the porous substructure becomes diluted, so called dilutive ICP (McCutcheon et al., 2006). The unmitigated dilutive ICP is considered to be the most dominant CP when the feed is towards 
active layer (McCutcheon et al., 2006), which can significantly decrease the net driving force, leading to a decline of water flux (McCutcheon et al., 2006). In addition, the feed container had a volume of $2 \mathrm{~L}$ with insufficient turbulence, low flow velocity and the relatively thick frame (0.5 $\mathrm{cm}$ ), which could result in a weak hydrodynamic shear force on membrane surface, thereby further enhancing the concentrative ECP. Furthermore, as a unique feature of the FO process, the bidirectional diffusion of solutes can also occur due to loss of draw solutes (Lee et al., 2010), leading to the decreases in water flux and water quality (Xie et al., 2012). In this study, the RSF demonstrated a positive relationship with the increased concentration of the draw solute (Fig. 3B), and it significantly increased from $1.3 \pm 0.9\left(0.5 \mathrm{M} \mathrm{NH}_{4} \mathrm{HCO}_{3}\right)$ to $9.4 \pm 1.1 \mathrm{~g} \mathrm{~N} \mathrm{~m}^{-2} \mathrm{~h}^{-1}(2 \mathrm{M}$ $\mathrm{NH}_{4} \mathrm{HCO}_{3}$ ). The increased RSF resulted in a large loss of draw solutes and accelerated water flux decline.

\subsection{Ion migration across FO membrane}

Reverse flux of $\mathrm{NH}_{4}{ }^{+}$and forward fluxes of $\mathrm{Na}^{+}$and $\mathrm{NO}_{3}{ }^{-}$when using $1 \mathrm{M}, 1.5 \mathrm{M}$ and $2 \mathrm{M}$ $\mathrm{NH}_{4} \mathrm{HCO}_{3}$ as draw solution, are depicted in Fig. 3C. As mentioned previously, the reverse solute flux of $\mathrm{NH}_{4}{ }^{+}$increased as the draw solute concentration increased and was observed up to 742.4 $m m o l m^{-2} h^{-1}\left(2 \mathrm{M} \mathrm{NH}_{4} \mathrm{HCO}_{3}\right.$ draw solution), which was slightly lower than a previous report that the RSF of $\mathrm{NH}_{4}{ }^{+}-\mathrm{N}$ reached $860 \mathrm{mmol} \mathrm{m}^{-2} \mathrm{~h}^{-1}$ when the deionized water and $\mathrm{NH}_{3}-\mathrm{CO}_{2}(1.8$ $\mathrm{M} \mathrm{NH}_{4} \mathrm{HCO}_{3}$ mixed with $0.2 \mathrm{M} \mathrm{NH}_{4} \mathrm{OH}, \mathrm{pH}=\sim 7.8$ ) was used as feed solution and draw solution, respectively (Lu et al., 2014). The forward flux of $\mathrm{Na}^{+}$was estimated at $9.6 \pm 0.4 \mathrm{mmol}$ $\mathrm{m}^{-2} \mathrm{~h}^{-1}$ while the forward flux of $\mathrm{K}^{+}$was ignorable, possibly because of its much lower concentration than that of $\mathrm{Na}^{+}$in the synthetic influent $(0.2 \mathrm{mM}$ vs. $5 \mathrm{mM})$. Interestingly, $\mathrm{Mg}^{2+}$ and $\mathrm{Ca}^{2+}$ were not detected in the feed or draw side. It was hypothesized that these cations might 
move across the membrane and react with $\mathrm{CO}_{3}{ }^{2-}$ to form calcium- and magnesium-containing precipitates. The forward diffusion of cations from the feed solution could promote the reverse diffusion of $\mathrm{NH}_{4}{ }^{+}$to make up the charge balance (Lu et al., 2014). Meanwhile, the forward diffusion of anions was also observed. For example, the forward flux of $\mathrm{NO}_{3}{ }^{-}$reached $3.6 \pm 1.1$ mmol m${ }^{-2} \mathrm{~h}^{-1}$ when applying $2 \mathrm{M} \mathrm{NH}_{4} \mathrm{HCO}_{3}$ as draw solution, while the anions such as $\mathrm{Cl}^{-}, \mathrm{PO}_{4}{ }^{3-}$ and $\mathrm{SO}_{4}{ }^{2-}$ were below detection limits in the draw side. Two transport mechanisms for nitrate permeation in FO process have been proposed: solution-diffusion mechanism and ion exchange mechanism (Irvine et al., 2013). In this study, $\mathrm{NO}_{3}{ }^{-}$and $\mathrm{Na}^{+}$from the feed solution can permeate through the membrane and maintain electroneutrality; alternatively, $\mathrm{NO}_{3}{ }^{-}$from the feed solution can exchange with $\mathrm{HCO}_{3}{ }^{-}$from the draw solution to maintain the charge balance. It remains unclear which mechanism plays a dominant role in this hybrid system. Furthermore, $\mathrm{NO}_{2}{ }^{-}$was detected in the draw side with a concentration below $0.1 \mathrm{mg} \mathrm{L}^{-1}$, which was reasonable because most of the produced $\mathrm{NO}_{2}{ }^{-}$was consumed by microorganisms in the feed side and the nitritationanammox reactor (Fig. 2B).

\subsection{The formation of biofilm on FO membrane}

The FO unit coupled with nitritation-anammox reactor led to the formation of biofilm on the membrane, likely affecting the water permeability across the membrane. The biofilm would contribute to the removal of reverse-fluxed ammonium. For example, nitrifiers and anammox bacteria could exist in the specific regions of biofilm due to DO gradient. To avoid affecting the microorganisms, no chemical treatment was applied to clean the FO membrane during the whole operating period. Instead, in situ backwashing was performed on day 53 and day 113 before starting using $0.75 \mathrm{M}$ and $1.5 \mathrm{M} \mathrm{NH}_{4} \mathrm{HCO}_{3}$, respectively. The dense cake layer formed on the $\mathrm{FO}$ 
unit was observed after continuous operation because of biomass growth (Fig. S3A). Given the relatively low water flux obtained with the increased draw solute concentration, the possibility and potential of biofouling could become apparent in the long-term operation of the OsAMX system.

The FO unit was chemically cleaned at the end of the experiment. The unit was taken out of the feed container for removing biofilm and washing with tap water, and then submerged in $0.3 \%$ $\mathrm{NaClO}$ solution for one day. Interestingly, the salt-like deposits were found in the draw chamber, which agrees that the mineral salt scaling can occur on the membrane surface when scale precursor ions (e.g., $\mathrm{Mg}^{2+}, \mathrm{Ca}^{2+}, \mathrm{SO}_{4}{ }^{2-}, \mathrm{CO}_{3}{ }^{2-}$, etc.) are present (Rahardianto et al., 2007). Considering the undetectable $\mathrm{Mg}^{2+}$ and $\mathrm{Ca}^{2+}$ in both the feed and the draw solutions together with the increased $\mathrm{pH}$ of the draw solution, these observed precipitates could be calcium- and magnesium-containing minerals, such as $\mathrm{CaCO}_{3}, \mathrm{MgCO}_{3}$, $\mathrm{CaMg}\left(\mathrm{CO}_{3}\right)_{2}$, etc. In addition, struvite $\left(\mathrm{MgNH}_{4} \mathrm{PO}_{4} \cdot 6 \mathrm{H}_{2} \mathrm{O}\right)$ precipitation could also occur with the suitable concentrations of ions and $\mathrm{pH}$ condition. For example, the $\mathrm{pH}$ of draw side was found to be over 8.5 when using $1.5 \mathrm{M}$ and $2 \mathrm{M} \mathrm{NH}_{4} \mathrm{HCO}_{3}$ as draw solution (Fig. S2), and such pH condition would benefit for struvite formation (Suzuki et al., 2002). These minerals could also deposit into the porous substructure of support layer, leading to a decrease of water flux. The fouled membrane achieved a water flux of $\sim 1.8 \mathrm{LMH}$ when using tap water and $0.5 \mathrm{M} \mathrm{NH}_{4} \mathrm{HCO}_{3}$ as feed and draw solutions, respectively, while the cleaned membrane achieved a water flux of $\sim 2.6 \mathrm{LMH}$. The permeability of the cleaned membrane recovered to more than $90 \%$ of the initial permeability, indicating that the FO membrane fouling in the OsAMX could be reversible. 


\subsection{Morphology of nitritation-anammox granules and biofilm on the FO membrane}

The OsAMX system was inoculated with a mixed culture containing sludge flocs and anammox granules. During the long-term operation, it was unavoidable that a small amount of biomass in the anammox effluent moved into the feed side because of the feed recirculation (Fig. 1). As a result, the biofilm was gradually formed on the FO unit (Fig. S3). The thick biofilm was mainly developed in the bottom part of the unit, likely due to easy access to oxygen. The FO membrane was able to completely retain biomass in the system, which was essential to accumulate those microorganisms with slow growth rates (e.g., anammox bacteria, AOB, etc.). The granules in the nitritation-anammox reactor were collected on day 126 , and one can see that the granules with reddish color have an average diameter of $2.8 \mathrm{~mm}$ (Fig. S4A). The unique porous structure was also observed on the surface of the granules, which could facilitate substrate transfer from the bulk to the inner part of the granules. The granule was relatively dense and had an irregular shape (Fig. S4B). The granules were mainly consisted of cocci and bacilli, which formed aggregates of cells (clusters or microcolonies) with tiny interspace that favored the compact feature of the granules. The smooth coccoid-shaped cells with diameters $<1 \mu \mathrm{m}$ (clusters) were presumably anammox bacteria (Kuenen, 2008), which was confirmed by FISH. Besides, the filamentous bacteria (Fig. S4C and S4D) were also observed to co-exist with cocci bacteria when enriching anammox bacteria with the seeds from upflow anaerobic sludge blanket (UASB) (Chamchoi \& Nitisoravut, 2007). A network of wispy, well-spread filamentous structures among the bacteria was observed with unknown functions (Fig. S4D).

\subsection{Characterization and evolution of microbial communities}


The spatial distribution of the functional bacteria in the granules and biofilm was visualized by FISH. EUB338, NSO190, AMX820, AMX368 and NIT3 probes were used to target most bacteria, ammonia-oxidizing $\beta$-Proteobacteria, Brocadia- and Kuenenia- like anammox bacteria, all anammox bacteria and Nitrobacter, respectively (Table S2). The FISH images show that AOB, anammox bacteria and NOB co-existed in the granules and biofilm, and anammox bacteria exhibited to be predominant (Fig. S5, S6 and S7). NOB was detected in both granules and biofilm due to the availability of oxygen, and they may perform completely nitrification by competing for nitrite with anammox bacteria.

Four amplicon libraries, namely GS-Initial, GS-0.5M, GS-1.5M and BF-1.5M, were constructed from biomass samples obtained initially from inoculant, on day 50 and on day 126, respectively. After quality filtering, 455,864 sequences were annotated, with 157,555 high-quality sequences obtained for the GS-Initial sample, 111,735 for GS-0.5M, 93,465 for GS-1.5M and 93109 for BF-1.5M. The microbial community structures at various taxonomic levels are shown in Fig. 4 and Fig. S8. At the genus level (Fig. 4A), more than 50\% of the sequences were not classified, indicating the novelty of microbial communities in this system compared to more commonly studied organisms that are better represented in current rRNA sequence databases. The results indicate that anammox bacteria were dominant in all granular samples (from $35.2 \%$ to $42.0 \%$ ), which are in accordance with the FISH observations. However, anammox bacteria accounted for only $8.2 \%$ in the biofilm sample possibly because the high DO concentration in the feed side inhibited their growth (Fig. S1). All the anammox bacteria discovered so far belong to the monophyletic family Candidatus Brocadiaceae (Ca. Brocadiaceae) in the phylum Planctomycetes (Fig. 4B and 4D), and sixteen anammox species from five genera have been 
proposed (Sonthiphand et al., 2014). In this study, three genera affiliated with anammox - Ca. Brocadia, Ca. Jettenia and Ca. Kuenenia - were detected (Fig. 4A) with Ca. Jettenia being the distinctly dominant anammox genus in all granules while $\mathrm{Ca}$. Brocadia was most abundant in the biofilm (Fig. 5, S9 and Table S3).

The changing community structures of the four samples (i.e., GS-Initial, GS-0.5M, GS-1.5M and BF-1.5M) suggested microbial succession occurs in the granules and biofilm under long term operation with oxygen in the OsAMX system. A remarkable increase in the relative abundance of $\mathrm{Ca}$. Brocadia occurred in granules after continuous operation, from $0.1 \%$ of GS-Initial to $10.8 \%$ of GS-1.5M. In contrast, the relative abundance of $C a$. Jettenia decreased from $32.6 \%$ of GS-Initial to 22.6\% of GS-1.5M, while Ca. Kuenenia declined from 9.3\% to 1.8\% (Fig. 5), indicating both of them could be inhibited by the selective pressure of dissolved oxygen level. This was confirmed by the relative abundance of anammox genera on the FO membrane, where Ca. Brocadia accounted for $86.6 \%$ of all anammox bacteria while Ca. Jettenia and Ca. Kuenenia accounted for $12.2 \%$ and $1.2 \%$, respectively (Fig. S9). Nitritation is considered to be the ratelimiting step for a completely autotrophic nitrogen removal process (Cho et al., 2011), which is consistent with the result that the concentration of the remaining nitrite was much lower than that of ammonium (Fig. 2A). The population shift from Ca. Jettenia and Ca. Kuenenia to $C a$. Brocadia was expected with an extended operating period, and the shift could be attributed to the higher tolerance for DO or the elevated RSF of Ca. Brocadia (Fig. S1 and 3B). However, our results do not agree with a previous report that the higher affinity of $C a$. Kuenenia for nitrite resulted in a population shift from Ca. Brocadia to Ca. Kuenenia stuttgartiensis (van der Star et al., 2008). Indeed, the niche differentiation among anammox genera such as $\mathrm{Ca}$. Brocadia, $\mathrm{Ca}$. 
Jettenia and $C a$. Kuenenia is still unclear. It was previously hypothesized that $C a$. Kuenenia is an affinity (K) strategist and $\mathrm{Ca}$. Brocadia is a growth rate (r) strategist, but this hypothesis has not been confirmed due to insufficient data of the half saturation constant $\left(\mathrm{K}_{\mathrm{S}}\right)$ and maximum specific growth rate $\left(\mu_{m}\right)$ of anammox bacteria (van der Star et al., 2008). Several other studies have also shown the shifts of anammox bacterial communities. For example, the dominant anammox taxa shifted toward $\mathrm{Ca}$. Brocadia fulgida for its capability to utilize acetate for nitrate reduction (Kartal et al., 2008). It was also shown that anammox population shifted from $C a$. Kuenenia sp. to Ca. Brocadia anammoxidans because of their different kinetic strategies (Isanta et al., 2015).

The dominant phyla in the granule samples are Planctomycetes ( 40\%), Chlorobi ( 30\%), Proteobacteria (5 10\%), Bacteroidetes (5 10\%), and Chloroflexi ( 5\%) (Fig. 4D). Anammox bacteria branch deeply within the phylum Plantomycetes (Sonthiphand et al., 2014). The class Brocadiae related to the Planctomycetacia contains all the known anammox bacteria, while Betaproteobacteria includes several groups of nitrifiers, denitrifiers and other N-cycle related microorganisms (Isanta et al., 2015). The phylum Nitrospirae (NOB) was only detected in GS$1.5 \mathrm{M}(\sim 0.1 \%)$, which differs from the biomass enriched in a membrane-aerated biofilm reactor for nitritation-anammox process (Li et al., 2016). Besides, Planctomycetes and Proteobacteria, Chlorobi, Chloroflexi, and Acidobacteria are the major components of chlorophototrophs so called green bacteria (Bryant et al., 2012). The organisms affiliated with Chloroflexi have been observed in anammox reactors (Cho et al., 2010), and may survive in these systems on the cellular compounds released from dead biomass and metabolites from anammox bacteria (Kindaichi et al., 2012). In addition, Chloroflexi are able to reinforce the granular structure with 
filamentous biomass (Li et al., 2009; Miura \& Okabe, 2008), which was also observed by SEM in our system (Fig. S4C and S4D).

Compared with granular samples, Proteobacteria was the most abundant phylum in the biofilm sample (26.4\%), while anammox bacteria accounted for only 8.2\% (Fig. 4C and 4D). Members of the orders Burkholderiales and Rhodocyclales, belonging to class Betaproteobacteria, are denitrifying bacteria (Pereira et al., 2014) (Fig. S8), which might be responsible for alleviating nitrate accumulation in the feed side (Fig. 2). Their abundance was found to be much higher in biofilm than granules (1.2\% and 9.4\%, respectively). Nitrosomonadaceae (AOB) within the class Betaproteobacteria accounted for only $0.1 \%$ (not shown in the Fig. 6 because of its abundance $<$ 0.5\%), which seems consistent with FISH observations of hybridized biofilm sample with Nso190 probe targeting Betaproteobacterial AOB (Fig. S7). Meanwhile, Nitrobacter (NOB) in the class Alphaproteobacteria was not identified, which did not agree with FISH results (Fig. S7). The reason for such low abundance of AOB and NOB in the biofilm remains unknown.

\section{Conclusions}

The OsAMX system could successfully eliminate the accumulation of reverse-fluxed ammonium in feed side during continuous operation over 160 days. The accumulation of nitrate was not observed due to the activities of denitrifying bacteria and forward solute flux of nitrate. The water flux was much lower than expected, likely due to CP, RSF and membrane fouling. Sequencing showed $\mathrm{Ca}$. Jettenia was the dominant anammox genus but decreased with time, while $\mathrm{Ca}$. Brocadia accounted for $86.6 \%$ of all anammox bacteria in biofilm. This population shift suggested that $\mathrm{Ca}$. Brocadia might possess higher tolerance for DO or RSF in the OsAMX system. 


\section{Acknowledgements}

This study was supported by the COE Dean's office incentive program at Virginia Tech and a grant from National Science Foundation (\#1358145). The authors would like to thank Kaisen Lin and Dr. Husen Zhang (Virginia Tech) for their help with DNA extraction. The authors are also greatly thankful to Dr. Yun Hu in the Department of Biological Systems Engineering at Virginia Tech for his assistant with confocal laser scanning microscopy.

\section{Supplementary data}

Supplementary data associated with this article (Tables S1-3 and Figures S1-9) can be found in the online version. 


\section{References}

1. Bryant, D.A., Liu, Z., Li, T., Zhao, F., Costas, A.M.G., Klatt, C.G., Ward, D.M., Frigaard, N.-U., Overmann, J. 2012. Comparative and functional genomics of anoxygenic green bacteria from the taxa Chlorobi, Chloroflexi, and Acidobacteria. in: Functional genomics and evolution of photosynthetic systems, Springer, pp. 47-102.

2. Caporaso, J.G., Kuczynski, J., Stombaugh, J., Bittinger, K., Bushman, F.D., Costello, E.K., Fierer, N., Pena, A.G., Goodrich, J.K., Gordon, J.I., Huttley, G.A., Kelley, S.T., Knights, D., Koenig, J.E., Ley, R.E., Lozupone, C.A., McDonald, D., Muegge, B.D., Pirrung, M., Reeder, J., Sevinsky, J.R., Turnbaugh, P.J., Walters, W.A., Widmann, J., Yatsunenko, T., Zaneveld, J., Knight, R. 2010. QIIME allows analysis of high-throughput community sequencing data. Nat. Methods 7(5), 335-6.

3. Caporaso, J.G., Lauber, C.L., Walters, W.A., Berg-Lyons, D., Huntley, J., Fierer, N., Owens, S.M., Betley, J., Fraser, L., Bauer, M. 2012. Ultra-high-throughput microbial community analysis on the Illumina HiSeq and MiSeq platforms. ISME J., 6(8), 16211624.

4. Chamchoi, N., Nitisoravut, S. 2007. Anammox enrichment from different conventional sludges. Chemosphere, 66(11), 2225-2232.

5. Cho, S., Fujii, N., Lee, T., Okabe, S. 2011. Development of a simultaneous partial nitrification and anaerobic ammonia oxidation process in a single reactor. Bioresour. Technol. , 102(2), 652-659.

6. Cho, S., Takahashi, Y., Fujii, N., Yamada, Y., Satoh, H., Okabe, S. 2010. Nitrogen removal performance and microbial community analysis of an anaerobic up-flow granular bed anammox reactor. Chemosphere, 78(9), 1129-1135.

7. Edgar, R.C. 2010. Search and clustering orders of magnitude faster than BLAST. Bioinformatics, 26(19), 2460-1.

8. Edgar, R.C. 2013. UPARSE: highly accurate OTU sequences from microbial amplicon reads. Nat. Methods 10(10), 996-998.

9. Irvine, G.J., Rajesh, S., Georgiadis, M., Phillip, W.A. 2013. Ion selective permeation through cellulose acetate membranes in forward osmosis. Environ. Sci. Technol. , 47(23), 13745-13753. 
10. Isanta, E., Bezerra, T., Fernandez, I., Suarez-Ojeda, M.E., Perez, J., Carrera, J. 2015. Microbial community shifts on an anammox reactor after a temperature shock using 454pyrosequencing analysis. Bioresour. Technol. , 181, 207-213.

11. Kartal, B., van Niftrik, L., Rattray, J., van de Vossenberg, J.L.C.M., Schmid, M.C., Sinninghe Damsté, J., Jetten, M.S.M., Strous, M. 2008. Candidatus 'Brocadia fulgida': an autofluorescent anaerobic ammonium oxidizing bacterium. FEMS Microbiol. Ecol. , 63(1), 46-55.

12. Kindaichi, T., Yuri, S., Ozaki, N., Ohashi, A. 2012. Ecophysiological role and function of uncultured Chloroflexi in an anammox reactor. Water Science \& Technology, 66(12), 2556-2561.

13. Kuenen, J.G. 2008. Anammox bacteria: from discovery to application. Nat. Rev. Microbiol. , 6(4), 320-326.

14. Lee, S., Boo, C., Elimelech, M., Hong, S. 2010. Comparison of fouling behavior in forward osmosis (FO) and reverse osmosis (RO). J. Membr. Sci., 365(1), 34-39.

15. Li, X.-R., Du, B., Fu, H.-X., Wang, R.-F., Shi, J.-H., Wang, Y., Jetten, M.S., Quan, Z.-X. 2009. The bacterial diversity in an anaerobic ammonium-oxidizing (anammox) reactor community. Syst. Appl. Microbiol. , 32(4), 278-289.

16. Li, X., Lu, Y., He, Z. 2015. Removal of reverse-fluxed ammonium by anammox in a forward osmosis system using ammonium bicarbonate as a draw solute. J. Membr. Sci., 495, 424-430.

17. Li, X., Sun, S., Badgley, B.D., Sung, S., Zhang, H., He, Z. 2016. Nitrogen removal by granular nitritation-anammox in an upflow membrane-aerated biofilm reactor. Water Res., 94, 23-31.

18. Linares, R.V., Li, Z., Sarp, S., Bucs, S.S., Amy, G., Vrouwenvelder, J.S. 2014. Forward osmosis niches in seawater desalination and wastewater reuse. Water Res., 66, 122-139.

19. Lu, X.L., Boo, C., Ma, J., Elimelech, M. 2014. Bidirectional diffusion of ammonium and sodium cations in forward osmosis: Role of membrane active layer surface chemistry and charge. Environ. Sci. Technol. , 48(24), 14369-14376.

20. Lutchmiah, K., Verliefde, A.R.D., Roest, K., Rietveld, L.C., Cornelissen, E.R. 2014. Forward osmosis for application in wastewater treatment: A review. Water Res., 58, 179197. 
21. McCutcheon, J.R., McGinnis, R.L., Elimelech, M. 2006. Desalination by ammoniacarbon dioxide forward osmosis: influence of draw and feed solution concentrations on process performance. J. Membr. Sci., 278(1), 114-123.

22. McCutcheon, J.R., McGinnis, R.L., Elimelech, M. 2005. A novel ammonia-carbon dioxide forward (direct) osmosis desalination process. Desalination, 174(1), 1-11.

23. Mi, B., Elimelech, M. 2008. Chemical and physical aspects of organic fouling of forward osmosis membranes. J. Membr. Sci., 320(1), 292-302.

24. Mi, B., Elimelech, M. 2010. Organic fouling of forward osmosis membranes: fouling reversibility and cleaning without chemical reagents. J. Membr. Sci., 348(1), 337-345.

25. Miura, Y., Okabe, S. 2008. Quantification of cell specific uptake activity of microbial products by uncultured Chloroflexi by microautoradiography combined with fluorescence in situ hybridization. Environ. Sci. Technol. , 42(19), 7380-7386.

26. Okabe, S., Satoh, H., Watanabe, Y. 1999. In situ analysis of nitrifying biofilms as determined by in situ hybridization and the use of microelectrodes. Appl. Environ. Microbiol., 65(7), 3182-3191.

27. Pereira, A.D., Leal, C.D., Dias, M.F., Etchebehere, C., Chernicharo, C.A.L., de Araujo, J.C. 2014. Effect of phenol on the nitrogen removal performance and microbial community structure and composition of an anammox reactor. Bioresour. Technol. , 166, 103-111.

28. Qin, M., He, Z. 2014. Self-supplied ammonium bicarbonate draw solute for achieving wastewater treatment and recovery in a microbial electrolysis cell-forward osmosiscoupled system. Environ. Sci. Technol. Lett., 1(10), 437-441.

29. Rahardianto, A., Gao, J., Gabelich, C.J., Williams, M.D., Cohen, Y. 2007. High recovery membrane desalting of low-salinity brackish water: Integration of accelerated precipitation softening with membrane RO. J. Membr. Sci., 289(1-2), 123-137.

30. Shaffer, D.L., Werber, J.R., Jaramillo, H., Lin, S.H., Elimelech, M. 2015. Forward osmosis: Where are we now? Desalination, 356, 271-284.

31. Sonthiphand, P., Hall, M.W., Neufeld, J.D. 2014. Biogeography of anaerobic ammoniaoxidizing (anammox) bacteria. Front. Microbiol., 5, 399. 
32. Suzuki, K., Tanaka, Y., Osada, T., Waki, M. 2002. Removal of phosphate, magnesium and calcium from swine wastewater through crystallization enhanced by aeration. Water Res., 36(12), 2991-2998.

33. van der Star, W.R.L., Miclea, A.I., van Dongen, U., Muyzer, G., Picioreanu, C., van Loosdrecht, M.C.M. 2008. The membrane bioreactor: A novel tool to grow anammox bacteria as free cells. Biotechnol. Bioeng. , 101(2), 286-294.

34. Wang, Q., Garrity, G.M., Tiedje, J.M., Cole, J.R. 2007. Naïve Bayesian classifier for rapid assignment of rRNA sequences into the new bacterial taxonomy. Appl. Environ. Microbiol., 73(16), 5261-5267.

35. Xie, M., Nghiem, L.D., Price, W.E., Elimelech, M. 2012. Comparison of the removal of hydrophobic trace organic contaminants by forward osmosis and reverse osmosis. Water Res., 46(8), 2683-2692. 


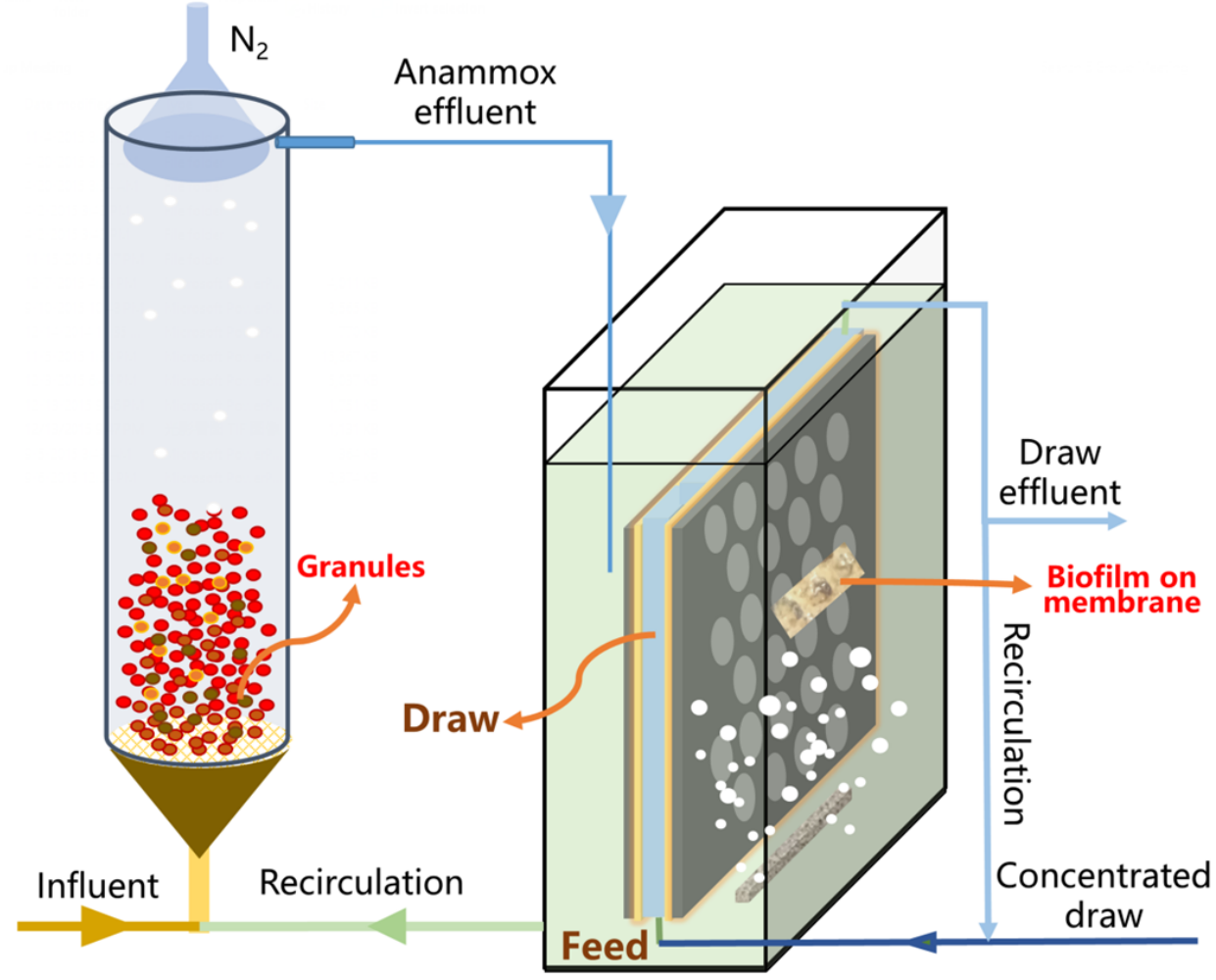

Figure 1. The schematic of the osmotic anammox (OsAMX) system consisting of a nitritationanammox reactor (left) and a FO unit (right). 

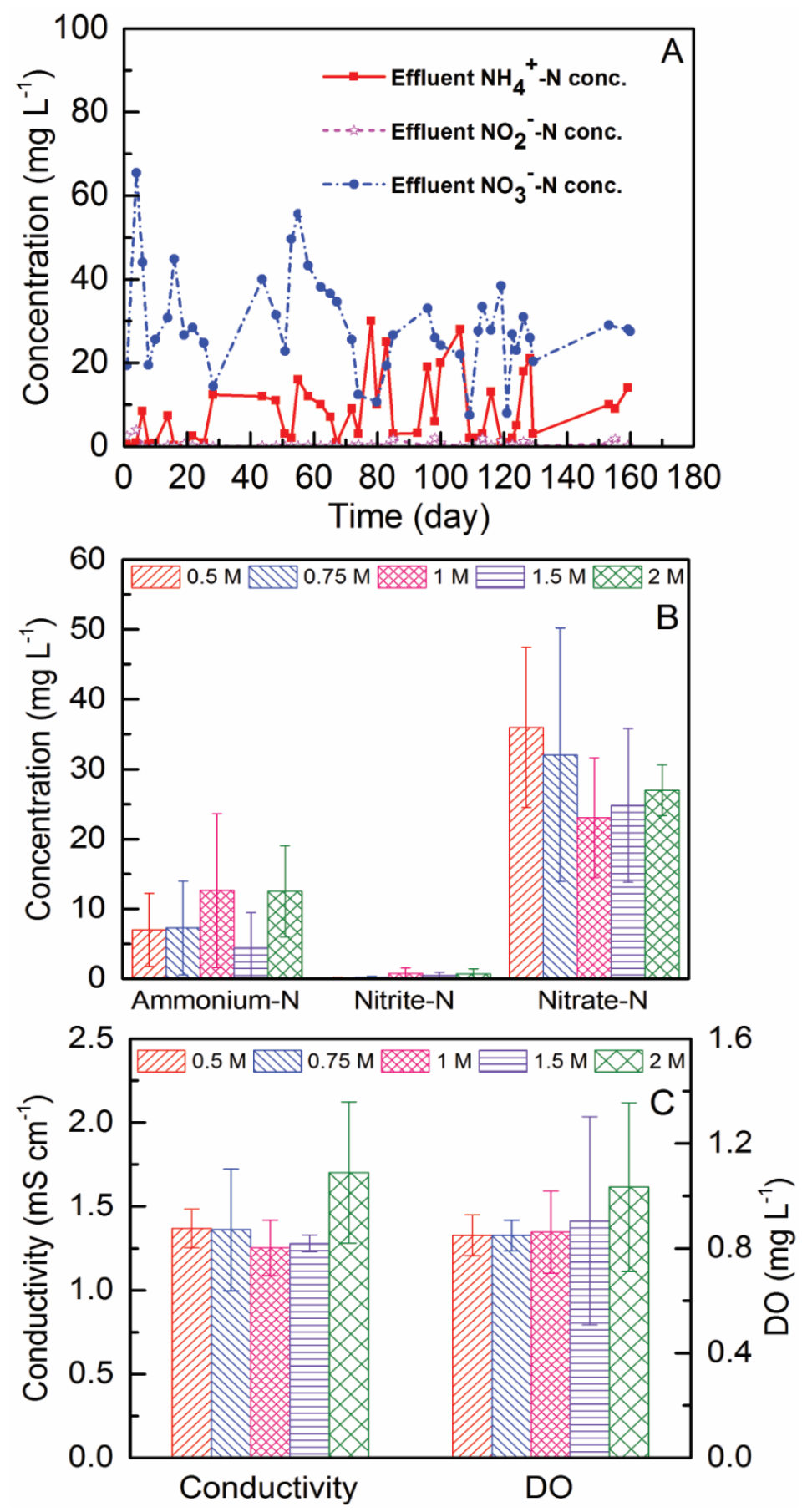

Figure 2. The long-term performance of the OsAMX system under various draw concentrations:

(A) the profiles of ammonium, nitrite, and nitrate in the nitritation-anammox reactor over 160 days, (B) the comparison of ammonium, nitrite, and nitrate concentrations, and (C) the profiles of conductivity and DO in the nitritation-anammox reactor. 

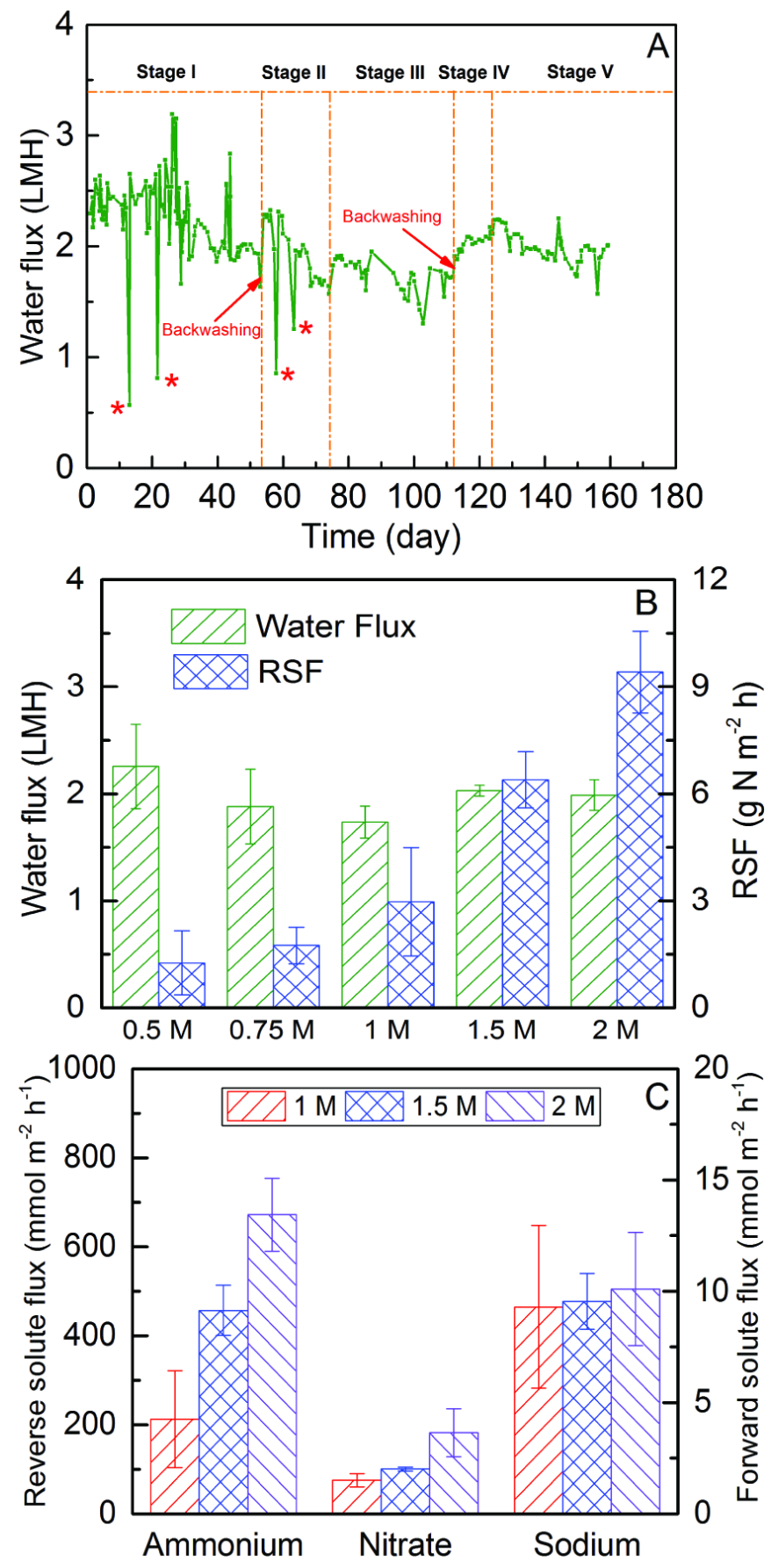

Figure 3. The long-term performance of FO unit: (A) the profiles of water flux over 160 days, (B) comparison of water flux and RSF under various draw concentrations, and (C) the profiles of forward fluxes of $\mathrm{NO}_{3}{ }^{-}$and $\mathrm{Na}^{+}$, and reverse flux of $\mathrm{NH}_{4}{ }^{+}$. Stars in Figure 3A indicate the depletion of the concentrated draw solution. 

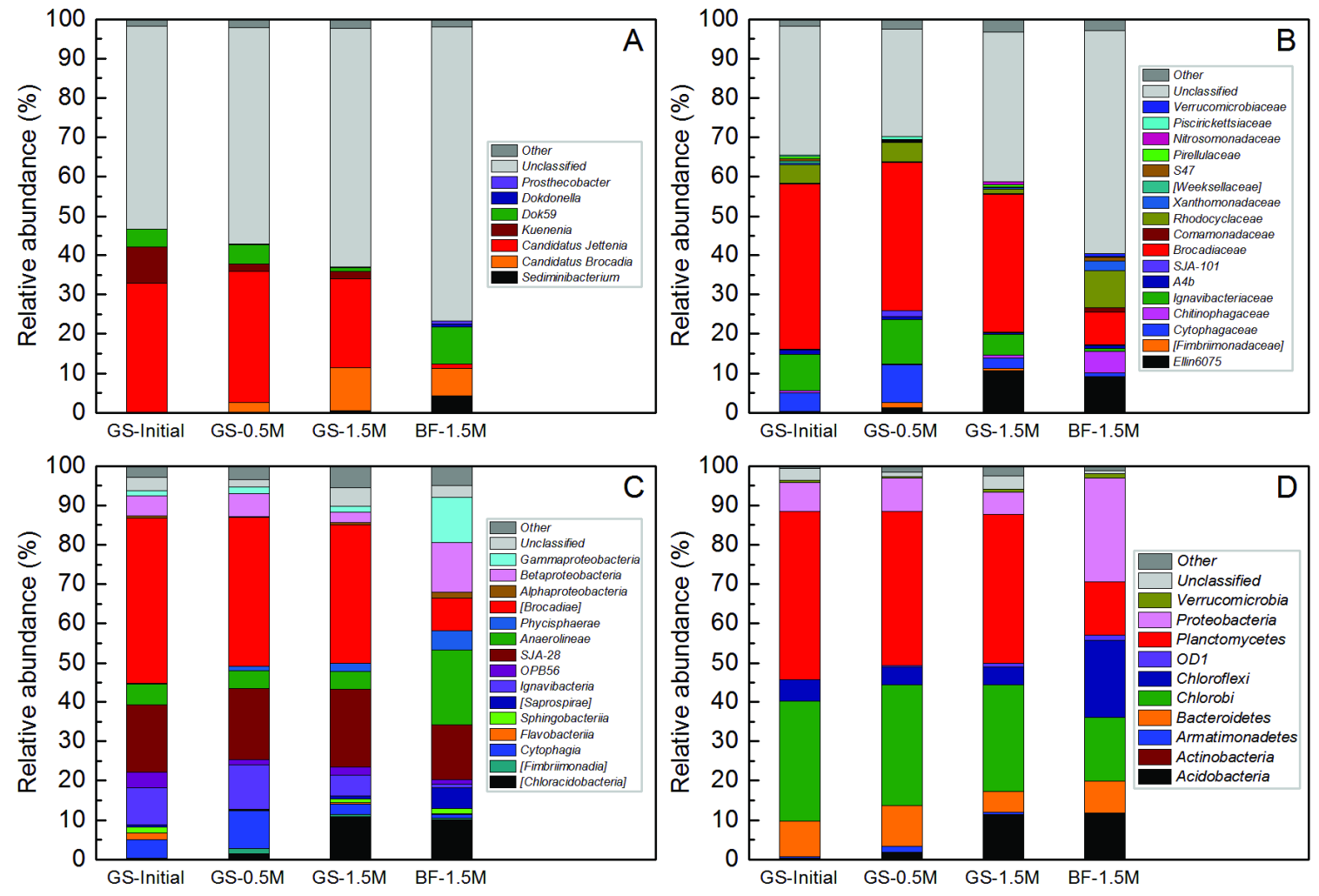

Figure 4. Bacterial community composition by sequencing: (A) at the genus level, (B) at the family level, (C) at the class level, (D) at the phylum level. "Other” represents all classified taxa that were $<0.5 \%$ in all samples for (A), (B) and (C), and $<1 \%$ for (D). "GS-Initial": granules in the inoculum; "GS-0.5M": granules sampled when operating with $0.5 \mathrm{M}$ draw; "GS-1.5M": granules sampled when operating with 1.5 M draw; "BF-1.5M": biofilm on the FO unit sampled when operating with $1.5 \mathrm{M}$ draw. 


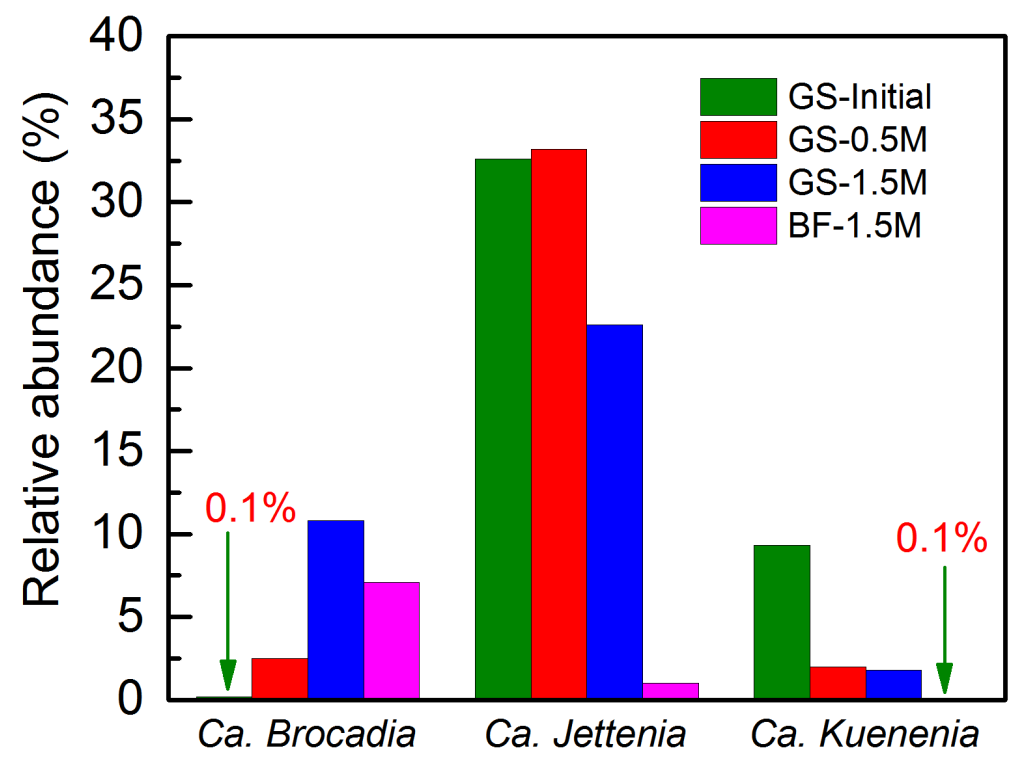

Figure 5. Shift of anammox bacterial genera in the microbial community. 


\section{Graphical abstract}

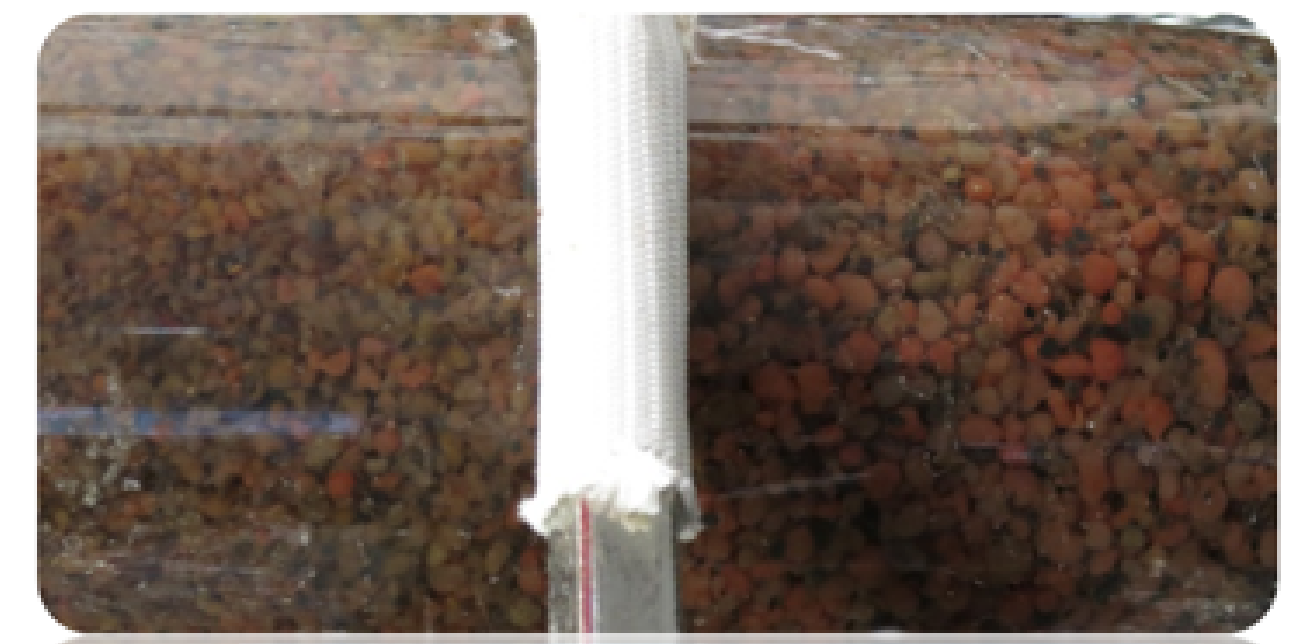

Granules in reactor

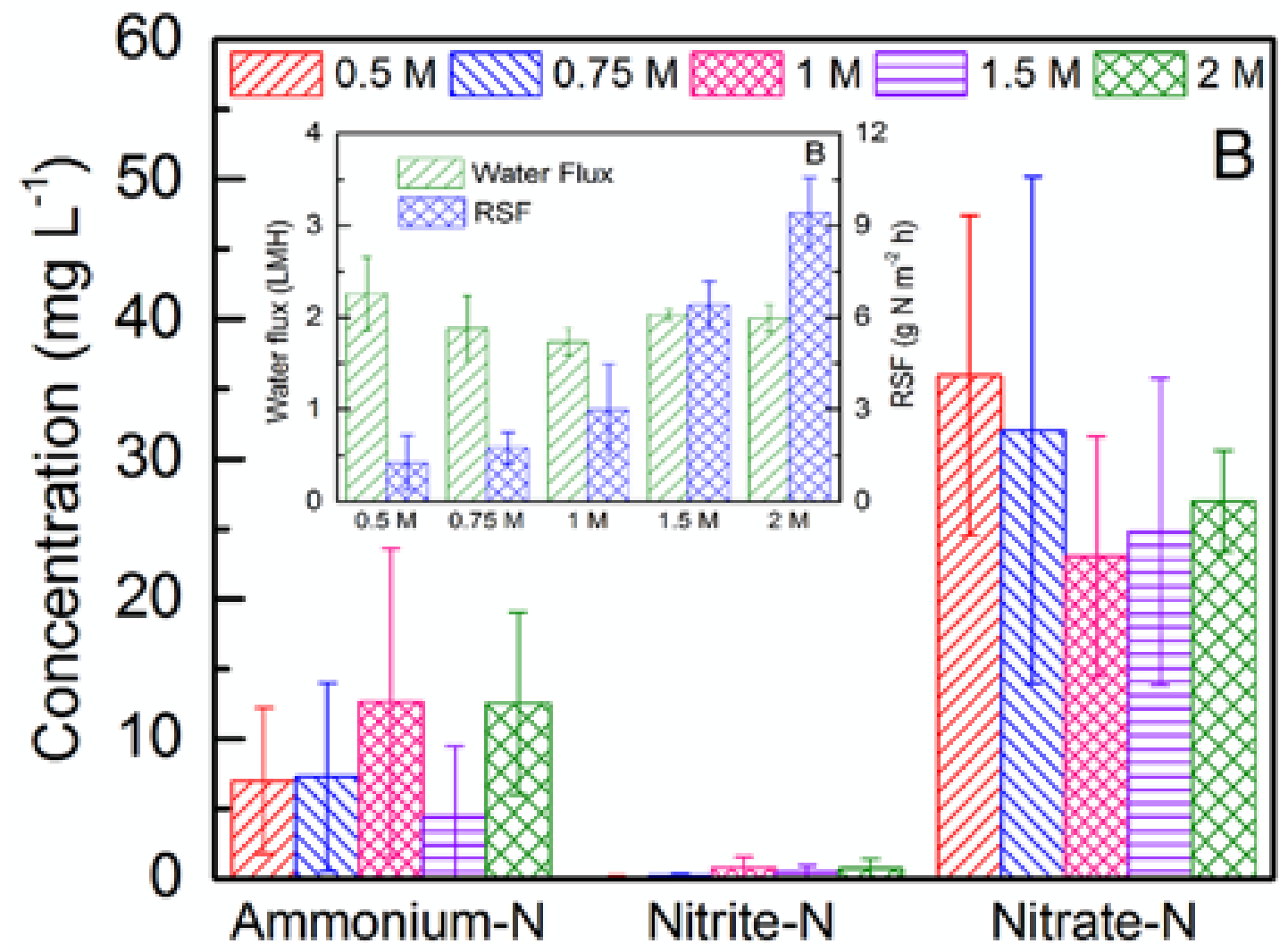

OsAMX system performance

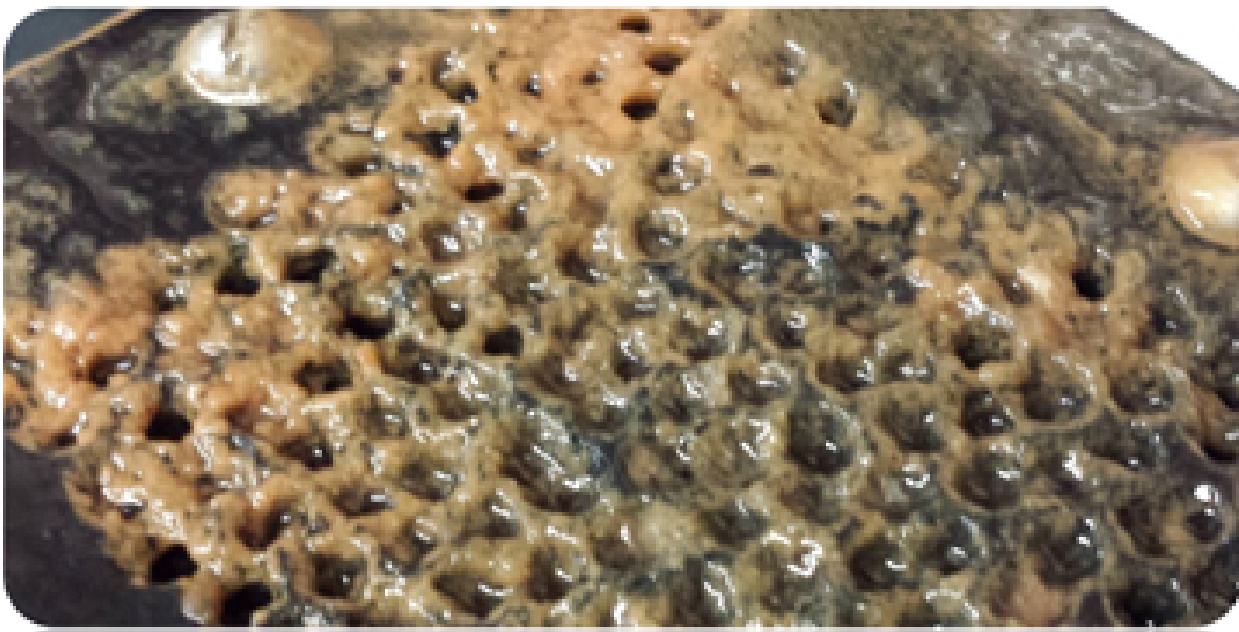

Biofiln on FO unit

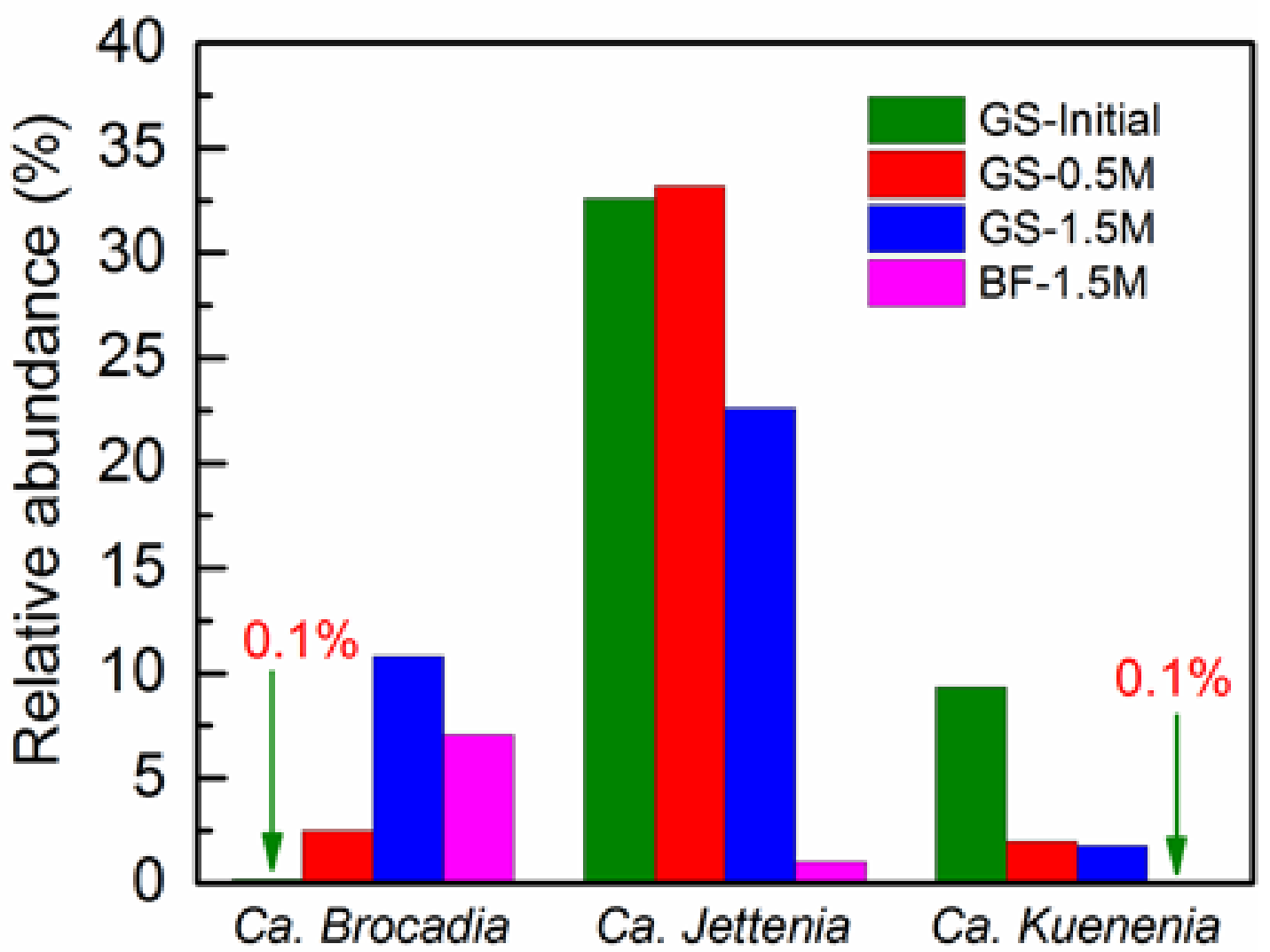

Shifts of anammox bacterial population 